\title{
Revisiting Deterrence: Legal Knowledge, Use Context and Arrest Perception for Cannabis*
}

\author{
PATRICIA G. ERICKSON and MARK VAN DER MAAS** \\ University of Toronto \\ ANDREW D. HATHAWAY \\ University of Guelph
}

\begin{abstract}
Deterrence research has evolved considerably since the 1970s when a favourite offence for study was the emerging phenomenon of widespread cannabis use among mainstream populations. The deterrent model of crime prevention has expanded far beyond the study of objective and subjective indicators of certainty and severity to encompass social support, moral evaluations, peer involvement and, most recently, risk sensitivity and situational factors. Most earlier research found no evidence of deterrence of cannabis use, a finding attributed to its low actual and perceived risk of arrest and changes in public attitudes. This interview study with adult experienced cannabis users drawn from a representative survey base in Toronto, Canada, where possession is still treated as a criminal offence, provides a more nuanced interpretation of deterrence. The authors found that users had generally inaccurate knowledge about the current law and penalties and believed they would avoid arrest in the future. However, they were not oblivious to the possibility of police intervention, and took precautions such as carrying small amounts and avoiding public use. Thus, users were not unaffected by the law, but rather these discreet practices illustrate the operation of restrictive deterrence, shaping their choices of when, where and how to commit the crime of cannabis use. Further research on deterrence should examine situated choices by risk-sensitive offenders, and should also include cross-national patterns of arrest and user risk perceptions. While cannabis continues to be prohibited by international treaties, the reality of widespread use presents opportunities for innovative deterrence studies into this normalised yet illegal crime. The variation in policies, penalty structures and enforcement across European nations, compared to those in other Western jurisdictions, can foster relevant research for a transatlantic discussion about global drug policy transformation.
\end{abstract}

Keywords: deterrence, cannabis, drug policy, drug arrests, public opinion, cross-national comparisons, Canada

Sociologický časopis/Czech Sociological Review, 2013, Vol. 49, No. 3: 427-448

\footnotetext{
* This research was funded by an operating grant from the Social Sciences and Humanities Research Council, Canada.

** Direct all correspondence to: Patricia G. Erickson, Department of Sociology, University of Toronto, 725 Spadina Avenue, Toronto, Ontario, Canada, M5S 2J4, e-mail: pat.erickson@ utoronto.ca; Mark van der Maas, Department of Sociology, and Collaborative Program in
}

C Sociologický ústav AV ČR, v.v.i., Praha 2013 


\section{Introduction}

Deterrence is the cornerstone of the global drug prohibition regime. The assumption reflected in the international treaties, that the relaxation or removal of drug laws would lead to more use, persists in most national policies [MacCoun et al. 2009]. The historical domination of prohibition has been countered by the shift towards drug policy reform in several countries [The Economist 2013]. Western Europe, the Netherlands, Portugal, Spain and the Czech Republic have already taken significant steps towards decriminalisation [Böllinger 2002; Sarkany 2012], South American countries such as Colombia and Uruguay have also moved in this direction, several US and Australian states have instituted civil penalties for possession, and Canada and Britain have considered various proposals for the modification of criminal penalties [Hyshka 2009b; Lenton 2009; Single 1989]. Nevertheless, the debate continues about the extent to which eliminating the criminal status or reducing the penalties for certain drugs will remove the deterrent effect and increase use. Therefore, it is critical to address this issue with available empirical data, considering the actual experience and behaviour of drug users. Such an investigation can contribute to discussion about a public health orientation that is gradually replacing the current domination of criminalisation as an international policy approach [Erickson et al. 1997]. Moreover, the variation in other core aspects of deterrence (i.e. penalty structure, enforcement, and public awareness) across national jurisdictions not only presents opportunities for comparative research but also can promote transatlantic dialogue on key aspects of drug policy.

Cannabis, the most widely used illicit drug in the world, has been the focus of considerable argument over the deterrent effects of criminal statutes and their enforcement. For over 40 years, there has been a sustained increase in the use of cannabis in Western nations, to the point that at least 150 million people are using the drug annually [Fielding et al. 2008]. More recent trends in national surveys suggest some levelling off in cannabis use [EMCDDA 2012; UNODC 2012; CADUMS 2011] while prevalence rates remain high among young people; close to a majority have experience with this drug before they leave their twenties [Adlaf, Begin and Sawka 2005; EMCDDA 2006; ESPAD 2012; Fergusson, SwainCampbell and Horwood, 2003; Johnson 1980; Lenton 2009; Parker 2005; Ritson 2003]. This expansion in cannabis use has occurred despite decades of a global prohibition regime and national criminalisation laws, often allowing severe penalties including imprisonment, and extensive local enforcement that unevenly targets the younger, low-level drug users [Fielding et al. 2008]. This situation has led many to conclude that drug prohibition is unjust and a failure, and that, minimally, the removal of the cannabis possession offence is called for [Le Dain 1972;

Addiction Studies, University of Toronto, M5S 2J4, e-mail: mark.vandermaas@utoronto.ca; Andrew D. Hathaway, Department of Sociology and Anthropology, University of Guelph, 50 Stone Road East, Guelph, Ontario, Canada, N1G 2W1, e-mail: hathawaa@uoguelph.ca. 
MacCoun and Reuter 2001]. However, aside from the policy issues, the scale of this challenge to the principles of deterrence has stimulated new directions in deterrence research, and provided an opportunity to examine how the threat of criminal sanctions affects lawbreaking according to an array of individual and situational characteristics beyond the certainty, severity and celerity of punishment [Stafford and Warr 1993]. Recently, increased attention has also been paid to public attitudes, drug markets, and the normalisation paradigm for understanding drug user behaviour [Aldridge, Measham and Williams 2011; Caulkins and Pacula 2006; MacCoun et al. 2009]. Nevertheless, the perceptual aspects of deterrence, that is, how potential or actual offenders perceive legal sanctions and their personal relevance, remain a key aspect of user practices with broad policy implications. The current study reported here addresses this issue with data from a country that retains criminalisation of users as its policy priority. This article will review the concept of deterrence, examine past research on its application to cannabis use, and then describe the Canadian legal and policy context which retains criminal penalties for possession. We will then present findings from a Toronto study of adult, experienced cannabis users' perceptions of the law and how they apply it to their own drug use behaviour. Since there is little actual empirical research on the specific issue of deterrence of cannabis use, this paper aims to augment this small body of knowledge and contribute to comparisons with European jurisdictions like the Czech Republic which reversed its criminalisation policy in 2010.

\section{A brief history of deterrence and its application to cannabis use}

The fundamental precept of deterrence underlying the criminal law is that threats of unpleasant penal sanctions will prevent crime [Zimring and Hawkins 1973]. In its most utilitarian, 18th-century form, it states that the severity, certainty and celerity of punishment will deter offending [Beccaria 1764, 1963]. The prevention of criminal activities in the population at large is referred to as general deterrence and the dissuasion of detected criminals from committing further offences is called specific deterrence [Andenaes 1974]. More recent conceptualisations have argued that general and specific deterrence are both rooted in the potential offender's indirect and direct experience of punishment, either of them or of others [Stafford and Warr 1993]. For policy purposes, these two expressions are interconnected in that it is the application of sanctions to individuals that makes the threat credible to the larger community. Early attempts at deterrence research examined fluctuations in crime rates (primarily focused on capital punishment) in relation to official measures (e.g. arrests, charges, sentencing, the proportion imprisoned or executed) or in terms of recidivism rates (e.g. re-offending) [Chambliss 1966]. Since the ultimate success of general deterrence rests on behaviour that does not occur, and hence is inherently unobservable [Gibbs 1975], conclusions related to the legal impacts of particular laws have tended to be inconsistent and 
uncritical of limitations in the data [Chiricos and Waldo 1970]. However, others have noted that punishment avoidance when a crime does occur without sanction (as opposed to those that are prevented) is observable, and may condition the responses of others, making them more or less willing to repeat or initiate such acts themselves [Stafford and Warr 1993]. Deterrence is also traditionally grounded in a rational choice model, whereby potential or actual offenders are assumed to have accurate knowledge of the penalties that would apply to them if they were caught [Becker 1968].

Until the upsurge in empirical research on deterrence in the 1970s, and the development of a more complex approach, the actual preventive effect of laws was more assumed than documented. Refining the deterrence model during the 1970s into a more perceptual theory, scholars recognised that a crucial link between the law and criminal action is how the would-be offender assesses the risks and rewards of committing an offence [Waldo and Chiricos 1972]. Further expansion to the deterrence model added factors such as social support for the activity, peer involvement, moral attribution, expectation of health or other adverse physical consequences, fear of long-range stigma, and the meaning attached to the specific penalty [Anderson, Chiricos and Waldo 1977; Meier and Johnson 1977; Silberman 1976]. More recent formulations add the notion of deterrability, to recognise that offenders vary also in their capacity and willingness to calculate the various risks and rewards related to possible penalties and other outcomes of their lawbreaking [Jacobs 2010; Pogarsky 2002]. Thus, while it is evident that laws designed to punish and deter are still a central concern in the study of formal social control, as well as public policy, there is now a much greater emphasis on social context, individual characteristics, and the ambiguity inherent in risk perceptions [Loughran et al. 2011; Piquero et al. 2011]. Increased understanding of the role of perceived benefits, not just perceived costs of offending, has also received attention, an area particularly relevant to illicit substance use [Baker and Piquero 2010].

Cannabis use was a favourite target in the new wave of deterrence research in the 1970s. This was in part because the legitimacy of the drug laws were being much debated in this era, but also because it quickly became evident that, despite quite severe criminal penalties, the law prohibiting cannabis use was being widely and increasingly broken. In contrast to the relatively small number of the populace who commit the most serious crimes, the new cannabis criminals provided ample sample sizes allowing a comparison of both compliant and non-compliant individuals, in a variety of legal contexts [Erickson 1980]. Indeed, many of the publications at the time with deterrence in their titles were found to be focusing on the crime of cannabis use [e.g. Chiricos and Waldo 1970; Meier and Johnson 1977; Silberman 1976].

While the numerous drug use surveys of the 1970s in Canada, the United States, Australia and Europe showed an ever increasing prevalence of cannabis use, it was difficult to relate these trends to the existing penalty structure in order 
to demonstrate whether any deterrent effect was operating. In Canada, where the drug laws were and still are a matter of federal jurisdiction, the Narcotic Control Act was uniform across all provinces. However, in the United States, where some states reduced penalties, it was possible to see if use patterns varied by sentence severity as set out in legislation. When Single [1989] compared cannabis use in national youth and adult surveys in the states that had reduced penalties in the 1970s to the states that had retained relatively severe or moderate penalties, he concluded that sentence variation had minimal impact on use levels. Further support for the lack of impact of sentence severity on cannabis use levels was demonstrated in the longitudinal survey of US high school seniors that found no marked differences in prevalence in decriminalised vs non-decriminalised states [Johnston 1980].

In the wave of perceptual deterrence research that focused on cannabis, a major and consistent finding was that users and non-users alike perceived a low likelihood of detection and arrest [Lundman 1986]. However, findings were mixed, with some studies observing, contrary to the deterrence doctrine, that users had a higher perceived certainty of punishment than non-users, while others found the expected inverse relationship [Silberman 1976; Teevan 1976; Waldo and Chiricos 1972]. The low perception of the chances of getting caught was seen as dwarfing any expectation of what a likely sentence might be, regardless of severity. When studies included a wider range of variables, such as perceived social support, peer use, health risks, and moral evaluation of cannabis use behaviour, the importance of perceived certainty was further diminished [Anderson, Chiricos and Waldo 1977; Erickson 1982; Meier and Johnson 1977]. In other words, factors other than the legal threat, not deterrence variables, were shown to be most important in decisions not to use cannabis [Erickson 1980: 90]. By the early 1980s, numerous studies had concluded that the threat of arrest had eroded over time, and combined with changing social attitudes about the greater acceptability of use, that the law was an impotent source of compliance [Lundman 1986]. Limitations of this research included the regionalism of studies, their tendency to focus on youth, the lack of information on enforcement practices, possible variation in the cost and availability of cannabis and the unknown extent to which the public was aware of existing statutes and practices [MacCoun et al. 2009].

Almost no studies have been done on the specific deterrence of cannabis use. In Canada, Erickson [1976, 1980] conducted a longitudinal study of 95 firsttime offenders found guilty of cannabis possession in the Toronto courts in 1974. At the time of sentence, most intended to continue use, and one year later $90 \%$ were still doing so, though 9\% had been arrested again for possession [Erickson and Murray 1986; Murray and Erickson 1987]. An official recidivism rate would therefore be one in ten, whereas the actual rate of continuing to offend, from selfreports, was nine out of ten. Very similar findings were described in an Australian study of convicted cannabis users [Chanteloup et al. 2005; Lenton and Heale 2000], and a longitudinal study of youth in New Zealand [Fergusson, Swain- 
Campbell and Horwood 2003]. In the latter, of a young but non-criminal sample aged 16-21, only $5.1 \%$ had ever been arrested for a cannabis offence, and 3.6\% convicted, but of these, $95 \%$ continued their use subsequently. In these studies, more frequent use was found to characterise those who had been detected and arrested. Although a core assumption of the classic deterrence doctrine is that potential offenders are aware of risks and shape their behaviour accordingly, the Canadian study found that even those who had experienced the concrete reality of a trip to court had an inaccurate knowledge of the law and potential penalties [Erickson 1980: 129-132]. This ignorance of the law was further confirmed in a series of semi-replications in the 1980s and 1990s [Erickson and Hyshka 2010]. While the New Zealand study did not assess the participants' legal knowledge of drug laws, the Australian studies indicated that users had an imperfect understanding of the innovative Cannabis Infringement Notice scheme [Chanteloup et al. 2005]. Moreover, MacCoun et al. [2009] found that similar proportions of the American public believed they could be jailed for cannabis possession in states that did and did not allow this sentence, and suggested that the publicity surrounding proposed changes to laws (whether occurring in practice or not) likely had more impact on perceptions than the actual implementation of the laws.

As is evident from the research reviewed above, most was conducted in Canada, the United States, Australia or New Zealand. Few studies specifically on cannabis and deterrence were found in the European (English-language) literature [Kilmer 2001, 2003], but some are less directly relevant. Considerable research has been conducted in European countries on cannabis use, within the evolving normalisation perspective [Adridge, Measham and Williams 2011; Cohen and Sas 1996; Peretti-Watel 2003; Sandberg 2012; Shiner and Newburn 1997; van Vliet 1990]. As these investigators document the widespread social acceptability of recreational cannabis use and the declining stigma held even by nonusers, in the face of existing (though often not enforced) criminal penalties, the question remains as to how users understand the law and its application and how that might vary between country and culture. A Dutch study of deterrence among adolescents did not include cannabis as an offence but rather as one component of a morality measure that implied it was wrong to use [Pauwels et al. 2011]. Other European research has examined the operation and impact of different types of drug markets. Comparing rates of use in the United States and the Netherlands, investigators found that penalisation of cannabis did not reduce prevalence, and moreover, accessibility in a city like San Francisco was very similar to that in Amsterdam [Reinarman 2009; Yacoubian 2008]. Shifts to more tolerant attitudes to drug use are seen as crucial differences separating European from the more punitive American and Canadian drug policies [Böllinger 2002]. Research on the deterrence of cannabis use dwindled in the 1980s and 1990s, as criminologists turned their theoretical and empirical sights on more conventional predatory crimes and deterrable offenders [Pogarsky 2002]. Reviews of these evolutionary developments are available and will not be reviewed here [see Bush- 
way and Reuter 2008; Pratt et al. 2006; Sherman 1993; Tittle 1980] other than to note that the obvious lack of evidence of cannabis deterrence in the traditional certainty/severity framework seemed to be accepted and not of great interest to more contemporary researchers.

Jacobs' [2010] recent formulation of risk sensitivity as a precondition of deterrability is of considerable relevance in helping to re-energise this discussion and understand the current persistent behaviour of cannabis users. This is because it takes us beyond intention or commitment to offend, whatever the context of sanction certainties and severities, into the situated decision-making of the actors themselves. As Jacobs says, 'deterrence is situational; it asks whether a specific offender committing a specific offense can be deterred' [2010: 430]. Similarly, restrictive deterrence, as articulated by Gibbs [1975: 33], refers to 'tactics employed by individuals to evade detection', but has had little empirical application until more recently. This formulation describes the process that a would-be offender engages in, with the expectation that it will reduce his or her chances of detection, such as taking situational measures to reduce the risk of detection, and or displacing the crime to a different place and time [Jacobs 2010: 433]. Thus the prospect of arrest for a crime may be thwarted by situational measures that influence a risk-sensitive offender. Those who are insensitive to risk may feel invincible and believe they are immune to detection and punishment

While restrictive deterrence may reduce the frequency of offenses, it may also simply defer their commission, or re-locate them to a less detectable location. As yet, few studies have considered its relevance to drug use. One exception is the continued research by an Australian team [Barratt et al. 2005] which used the term 'marginal deterrence' in a similar way to restrictive deterrence to describe the situational aspects of obtaining cannabis as mainly unaffected by the new Cannabis Infringement Notice. Piquero et al. [2011] considered this perspective in relation to the ways in which substance use, and particularly intoxication, might condition the sensitivity to sanction threats. Gallupe, Bouchard and Caulkins [2011] examined the operation of restrictive deterrence in their longitudinal study of police arrest records for offences that mainly involved cultivation and drug selling; however, they found that changes in behaviour (different drugs, amounts and locations) led to more rather than fewer arrests. Since this analysis was restricted to those that were caught, it is a limited test, and did not involve self-reports of strategies. An interview study of cannabis users in New York described the avoidance of public smoking as a kind of etiquette to evade police detection that also exemplifies the operation of restrictive deterrence [Ream et al. 2010]. Similarly, Elliott, Golub and Dunlap [2012], conducting research on users' knowledge of cannabis policing in New York, illustrated the importance of what users knew or expected from the police, not just the laws, in shaping their use environment. 


\section{The Canadian context}

The untested assumptions of the deterrent effectiveness of sentence severity are evident in the history of Canadian drug laws, with penalties starting at one-year imprisonment in 1911, expanding with whipping and mandatory minima over the next decades, and culminating in life imprisonment by 1961 [Giffen, Endicott and Lambert 1991]. These penalties applied to all the substances labelled in law as narcotics, including cannabis, heroin and cocaine. With the upsurge in cannabis use in the late 1960s, a royal commission was created to examine the reasons and recommend a suitable response; it did so by tackling the deterrence issues directly. The Le Dain Commission of Canada (1969-1973) was ground-breaking in its adoption of the principle of cost-effectiveness to guide their assessment of the appropriateness of the criminal law as the primary tool of social policy to contain and prevent drug use [Le Dain 1972: 275]. Its analysis, however, focused more on the costs of criminalisation rather than the presumed deterrent benefits because 'we cannot put in question the assumption which underlies the whole of our criminal law' [Le Dain 1972: 289]. They did speculate that the rates of cannabis use would 'double' if it were legalised; a survey conducted that time showed $3.5 \%$ of the population had tried cannabis and $1 \%$ reported past year use [Le Dain 1973]. Now, several decades later, with the same framework of criminal prohibition in place, nearly half of Canadian adults $(44.5 \%)$ have tried the drug and about $14 \%$ have used it in the past year, though rates have declined slightly in the late 2000s; nevertheless, these statistics reflect about 4 million current (past year) users [Adlaf, Begin and Sawka 2005; CADUMS 2011]. Nor have any police reports, interview studies with users, or student surveys indicated a shortage of cannabis in an ever burgeoning market [Bouchard and Nguyen 2010; Erickson 1989; Hathaway 2004]. This evidence appears, indeed, to put the effectiveness of the criminal law in question in relation to the crime of cannabis possession.

Despite what appears to be an obvious failure of deterrence, and several unsuccessful attempts to reform cannabis laws, the Conservative government elected in 2007 has affirmed the continuation and expansion of punitive measures for drug offences [Erickson and Hyshka 2010; Hathaway and Tousaw 2008; Hyshka 2009a]. Recent legislation (2013) imposes a mandatory minimum jail sentence for possession of six plants. Thus, it is timely to examine more recent research that explores the factors that shape cannabis users' persistent disregard of the law, in Canada and elsewhere, and fail to prevent so many users engaging in behaviour that is prohibited by international treaties and national statutes. Under the Controlled Drugs and Substances Act, cannabis possession of any amount in Canada is still technically punishable by a 1000 CAD fine and imprisonment of six months for a first offence of a small amount, though small fines and discharges are the most common outcomes [Hyshka, Erickson and Hathaway 2011]. This is in sharp contrast to the decriminalisation of possession in Portugal and the Czech Republic, the availability of cannabis in Dutch coffee shops, and the cooperative farming 
Table 1. Charges for drug offences in Canada, 2010

\begin{tabular}{lrrrc}
\hline Drug offence & Number & Rate & $\%$ & $\begin{array}{c}\text { Percentage } \\
\text { change } \\
\text { from 2009 }\end{array}$ \\
\hline Possession - cannabis & 56870 & 167 & 52.4 & 14 \\
$\begin{array}{l}\text { Possession - cocaine } \\
\text { Possession - other }\end{array}$ & 7256 & 21 & 6.7 & -6 \\
$\begin{array}{l}\text { Trafficking/production/distribution } \\
\text { cannabis }\end{array}$ & 9462 & 28 & 8.7 & 14 \\
$\begin{array}{l}\text { Trafficking/production/distribution } \\
- \text { cocaine }\end{array}$ & 97256 & 54 & 16.8 & 10 \\
$\begin{array}{l}\text { Trafficking/production/distribution } \\
- \text { other }\end{array}$ & 6956 & 20 & 6.4 & -4 \\
Total & 108529 & 318 & 100 & 10 \\
\hline
\end{tabular}

Source: Statistics Canada [2010].

of cannabis in Spain [The Economist 2013; Csete 2012], all reflecting a wider range of less criminalising policy options for cannabis and other illicit substances.

In Canada, there has been limited media attention to drug policy in recent years, likely leading to little awareness among the public of the extent to which simple possession is still a focus of enforcement, producing new waves of cannabis criminals annually. The rate of offences climbed steadily beginning in the early 1990s and peaked in 2001 at about 225 per 100000 -one of the highest reported cannabis arrest rates in the world [Statistics Canada 2010]. Total criminal convictions for cannabis possession, with the accompanying criminal records, now number over 1.5 million, and about half of all drug arrests in Canada are for cannabis possession. In a time of declining crime rates, it is one of the few crimes to show an upward trend. Cannabis outstrips all other drugs combined in the criminal justice response. In 2010, 56870 cannabis possession offences were recorded, an increase of $14 \%$ over the previous year. At the same time, public attitudes have consistently supported penalty reduction or legal regulation of cannabis [Adlaf, Begin and Sawka 2005; Hathaway, Erickson and Lucas 2007]. A recent Canadian study in four provinces, for example, found that the majority of experienced, socially integrated adult cannabis users did not know that possession of small amounts was still illegal, or else thought the police would ignore all but the most blatant public use [Brochu et al. 2011]. Yet prior research has found that the amounts of cannabis that form the basis of a possession charge have been uniformly small in Toronto, generally less than five grams [Erickson 1980; Erickson and Murray 1986; Erickson and Hyshka 2010], although no national data are available. 
Given this considerable disjunction between the prohibition policy, lenient public attitudes, high use levels and harsh criminal penalties, it is relevant for ongoing policy discussions to consider to what extent the users know and evaluate the legal threat and relate it to their own drug use behaviour. Why do so many users apparently not perceive the law as relevant to them, or do not believe they will be caught, or develop ways to evade capture?

\section{Methods}

Unlike most studies of cannabis users that recruit through advertising and snowball sampling techniques [Hathaway 1997, 2004], the data presented in this multi-faceted study are derived from in-depth interviews conducted with users recruited via a population sample [Hathaway, Kirst and Erickson 2013]. A twostage mixed-method design was employed to locate and interview-eligible cannabis-using respondents living in the city of Toronto in 2004. Stage one involved a brief, randomly selected household survey of adults, followed by a second stage consisting of a semi-structured interview, one-two hours in duration, with those eligible cannabis users who verbally agreed to a follow-up appointment. Overall, 92 respondents were successfully contacted and interviewed in person at a downtown research office between October 2004 and July 2005, and an additional 30 respondents were recruited by means of chain referral from these respondents, for a total of 122 participants. Since we found no apparent bias due to non-response between eligible respondents who did and did not agree to the interview, we are confident this sample is more fully representative than those gathered through non-random convenience designs [Hathaway et al. 2010, 2013; Reinarman 2009]. When a survey includes questions about illegal conduct, a fairly high degree of non-response is typically expected. However, levels of participation in Canadian drug studies including this one are within expected standards [Adlaf, Begin and Sawka 2005], and self-reports on drug use have been shown to be valid [Harrison 1997]. The trend towards greater social acceptance of cannabis may also reduce reluctance among users to participate in survey research of this nature [Reinarman, Cohen and Kaal 2004]. Moreover, while the added cases were non-randomly recruited, they were still derived from a larger and more typical base of adult cannabis users than ordinarily represented in a convenience sample or one of arrestees [see also Hathaway et al. 2010].

In stage one, the initial questionnaire items included personal experience with cannabis in terms of lifetime prevalence, patterns of consumption, and accurate knowledge of the legal penalty. This brief ten-minute survey was administered by telephone (to residential households and individual cell phone numbers in the 416 exchange for metropolitan Toronto) in October and November of 2004 by the University of Toronto's survey research centre. Interviewers asked to speak to the person 18 or older whose birthday was nearest the day of the call. In total, 1440 calls were successfully completed and definitively yielded an eli- 
Table 2. Demographic profile of the sample of cannabis users

\begin{tabular}{lcc}
\hline & Number & $\%$ \\
\hline Mean age & 35.9 & \\
\% female & 42 & 34.7 \\
Have a steady partner & 77 & 63.6 \\
Have children & 32 & 27.8 \\
Employed (full or part time) & 85 & 70.3 \\
Ever unemployed last 2 years & 30 & 24.6 \\
Ever arrested for drugs & 15 & 12.3 \\
Heavy users (daily) & 32 & 26.2 \\
\hline
\end{tabular}

Source: Authors.

Note: Total $N=122$; both random and chain referral groups.

gible respondent, and of these, 1081 persons completed the brief phone survey. In stage two, participants were informed of the confidential nature and purpose of the study, and their anonymity assured. Respondents eligible for follow-up were those who reported that they had used cannabis on 25 or more occasions $(N=274)$. This low use threshold was selected to facilitate recruitment of a sufficient number of 'experienced' users, while excluding very occasional or shortterm experimental users, following the Dutch precedent [Cohen and Sas 1996]. The in-depth interview probed for more details on the reasons for use, positive and negative reactions, and their views on the risks of arrest, obtaining drugs, and other topics pertaining to the social meanings of their drug use [Hathaway, Kirst and Erickson 2013]. Comments were recorded verbatim by the interviewer at the time.

Sample characteristics: The mean age of participants was 35.9 years, with a standard deviation of 12 years, indicating that the sample is well distributed across the different age groups. About a third of the respondents were women $(35 \%)$, which is consistent with representative samples of experienced cannabis users collected in other studies using similar methods [Reinarman, Cohen and Kaal 2004], and which reflects the higher prevalence of cannabis use by men. Two-thirds (64\%) had a steady partner, less than a quarter $(22 \%)$ lived alone, and whereas most had been employed at the time of the study ( $46 \%$ full-time and $25 \%$ part-time), one-quarter of respondents reported being unemployed at some point in the previous two years, and $12 \%$ reported a prior drug arrest. 


\section{Findings}

We will first present their profile as cannabis users, followed by a description of their supply sources and access, and their legal knowledge of the relevant Canadian drug law. Then we will relate this knowledge to their perceived risk of arrest, and its link to other factors, and elaborate their personal comments on the ways they view arrest and the tactics they adopt to avoid this intervention. When responding, the respondents were encouraged to elaborate on their experiences and perceptions of the legal threat. In the discussion of the findings, we will consider whether and to what extent cannabis users are risk sensitive or insensitive, based on their qualitative comments. Due to the small sample size, and the limitations of missing data, the analysis is primarily descriptive rather than multivariate. Since the chain referral segment of the sample did not complete the stage one screening questionnaire, which asked specifically about their knowledge of the law, Table 3 (and the related summary in Table 4a) is based on the randomly selected respondent group, whereas the perceived likelihood of arrest and elaboration of strategies are based on the full sample.

Marijuana use profile: While all had a history of use, most respondents qualified as current users; $60 \%$ had smoked marijuana in the last 30 days and $80 \%$ had used it in the year prior to the survey. The average age of first use was 16.6 years $(\mathrm{SD}=4.0)$ and the average age at which participants started using marijuana regularly was 19.2 years $(\mathrm{SD}=5.2)$. The mean age of heaviest (daily) use was 2.5 years later (21.7 years, $\mathrm{SD}=6.1)$. One in four respondents reported using daily (at least once a day or more) during the past month. Most (72\%) said they hid their use of marijuana from some people, and a large majority (84\%) thought contact with other users had an important influence on their own use patterns. When participants were asked whether they had experienced any serious problems due to marijuana use, only 7 of them replied affirmatively - two of these had been arrested previously and charged with possession. A minority of respondents $(N=27)$ reported often using in public places such as outdoors, in a nightclub, or in somebody's car. Most users restricted their use to private settings-at home, or at a friend's place or house party, for example.

Supply sources and access to cannabis: Most respondents got their cannabis from a friend or friends who either sold it or had a connection with a dealer. Very few (only six) obtained it from unknown 'street dealers' or from growers or grew cannabis themselves. Participants were also asked how long it would take them to get 3.5 grams (or $1 / 8$ ounce) of cannabis. About half of them indicated it would take them less than a couple of hours, and one in four reported that they could obtain the same amount in less than 30 minutes. This reflects a similar pattern of access for adults as the social supply networks described by Coomber and Turnbull [2007] among British adolescents.

Users' knowledge of the law and the perceived risk of arrest: Not surprisingly, respondents almost unanimously supported the view that cannabis (marijuana) 
Table 3. Respondents' knowledge of cannabis penalties for simple possession

\begin{tabular}{lccc}
\hline Response & Frequency & $\%$ & Valid \% \\
\hline Penalty up to 1000 CAD first offense & 6 & 4.9 & 8.3 \\
6 months jail and/or 1000 CAD fine & $\mathbf{2 9}$ & $\mathbf{2 3 . 8}$ & $\mathbf{4 0 . 3}$ \\
Discharge and automatic pardon & 7 & 5.7 & 9.7 \\
500 CAD for first offence & 6 & 4.9 & 8.3 \\
Only if consumed in a public place & 2 & 1.6 & 2.8 \\
None of the above & 8 & 6.6 & 11.1 \\
Don't know & 14 & 11.5 & 19.4 \\
Total & 72 & 59.0 & 100.0 \\
\hline
\end{tabular}

Source: Authors.

* correct penalty

Note: Total $N=92$, based on random sample; some missing data due to non-response.

laws should be made more lenient. We asked the question, 'Do you think our marijuana laws should remain as they are, be more like the laws for heroin (stricter), or be more like the laws for alcohol (more relaxed)?' Ninety-five percent of them favoured the latter option, with only one suggesting that the law should be stricter. To examine knowledge of the law, we asked respondents to identify the correct maximum penalty for simple possession of cannabis in Canada from several listed options-i.e. up to 1000 CAD fine for a first-offense, 6 months in prison and/or a 1000 CAD fine, discharge and automatic pardon, 500 CAD for a first offense, only if consumed in a public place, none of the above, don't know.

Forty percent of them correctly chose option two, which states: 'Under the Controlled Drugs and Substances Act, the penalty on summary conviction is a maximum of six months imprisonment and / or fine of up to $\$ 1,000$ for a first offence.' Thirty percent selected either 'none of the above' (11\%) or 'I don't know' (19\%), and the rest were almost equally divided between the other (incorrect) options. We also asked respondents if the marijuana law had any effect on their patterns of use. A greater proportion of users who accurately identified the charges for cannabis possession stated that they adjusted their use patterns because of the legal risk involved (55\%) compared to those who could not identify the penalty correctly $(30 \%)$. This difference was significant (chi-sq. $=4.478, p<.05)$.

About one-third of respondents in total said that their use patterns are affected by the law. To follow up, this group was asked an open-ended question requesting more detail on how the law affects their use. Their comments indicated that some see legal sanctions as a 'hassle' that 'add to paranoia' and can be 'a bit of a deterrent'. One observed that 'nobody wants to go to jail or pay a hefty 
Table 4a. Accurate knowledge of the law by whether legal sanctions affect use patterns

\begin{tabular}{lccc}
\hline Knowledge of the law & \multicolumn{3}{c}{ Do legal sanctions affect your use? } \\
& Yes & No & Total \\
\hline Accurate & $16(22.2 \%)$ & $13(18.0 \%)$ & $29(40.3 \%)$ \\
Inaccurate & $13(18.0 \%)$ & $30(41.7 \%)$ & $43(59.7 \%)$ \\
Total & $29(40.3 \%)$ & $43(59.7 \%)$ & $72(100 \%)$ \\
\hline
\end{tabular}

Source: Authors.

Note: Pearson chi-square 4.478, $p=.034$; Total $N=92$, based on a random sample; some missing data due to non-response.

fine'. In particular, some noted that the effect of the law was primarily related to maintaining a supply. 'You always think about the consequences when you go to get it', said one respondent. And another person stated: 'The legal sanctions prohibiting marijuana use don't pose any problems for me, but if it were legal it would be easier to get. I would be less cautious about procurement.'

Additional statistical analyses (not shown) detected no significant group differences between those with accurate knowledge of the law and those with inaccurate knowledge, with respect to their use levels, perceived risk of arrest, and their stated fear of being arrested, source of supply, nor ever having sold marijuana in the past. Demographic variables such as age and sex also showed no significant relationship with having accurate knowledge of the law. Non-significant relationships were also found for other variables of interest including hiding use from others, taking precautions to avoid arrest, and ever having been arrested for possessing marijuana. On a scale from 'not at all' to 'extremely like$1 y^{\prime}$, respondents were asked how likely they were to be arrested for possession of cannabis at some point in the future. Eighty-five percent said they were 'not at all' $(71 \%)$ at risk or 'unlikely' (14\%) to ever be arrested for possession. There was a significant difference between those who perceived none versus at least some risk of future arrest, in relation to a prior possession arrest (chi-sq. $=4.248, p>0.05$ ), using cannabis daily or more often $(10.51, p>0.01)$, and obtaining cannabis from a friend who is a dealer $(5.692, p>0.05)$. These findings suggest those with greater cannabis involvement also realistically assess their heightened risk of detection and arrest, while remaining undeterred.

Respondents indicated various strategies they believed would reduce their chances of arrest, namely avoiding use in public (or at least 'upwind of police', as one said) and 'just being smart' or 'subtle about it', or smoking only with 'close friends' in a 'safe' and 'private' place. Specific strategies employed by those who did at times smoke in public included carrying small amounts, in addition to being subtle or inconspicuous, or smoking only 'in out of the way places'. For example: 'I don't have more than $1 / 4$ ounce [7 grams] on me at any time ... I hide it 
Table $4 \mathrm{~b}$. Perceived likelihood of arrest by ever arrested for possession of cannabis

\begin{tabular}{lccc}
\hline \multirow{2}{*}{ Perceived likelihood of arrest } & \multicolumn{3}{c}{ Arrested for the possession of cannabis } \\
\cline { 2 - 4 } & Yes & No & Total \\
\hline None & $8(7.5 \%)$ & $72(67.3 \%)$ & $80(74.8 \%)$ \\
At least some & $7(6.5 \%)$ & $20(18.7 \%)$ & $27(25.2 \%)$ \\
Total & $15(14.0 \%)$ & $92(86.0 \%)$ & $107(100 \%)$ \\
\hline
\end{tabular}

Source: Authors.

Note: Pearson chi-square 4.248, $p=.039$; Total $N=122$; both random and chain referral groups; some missing data due to non-response.

Table 4c. Perceived likelihood of arrest by daily use

\begin{tabular}{lccc}
\hline Perceived likelihood of arrest & \multicolumn{3}{c}{ Use cannabis daily } \\
\cline { 2 - 4 } & No & Yes & Total \\
\hline None & $64(59.8 \%)$ & $16(15.0 \%)$ & $80(74.8 \%)$ \\
At least some & $13(12.2 \%)$ & $14(13.1 \%)$ & $27(25.2 \%)$ \\
Total & $77(72.0 \%)$ & $30(28.0 \%)$ & $107(100 \%)$ \\
\hline
\end{tabular}

Source: Authors.

Note: Pearson chi-square 10.51, $p=.001$; Total $N=122$; both random and chain referral groups; some missing data due to non-response.

Table 4d. Perceived likelihood of arrest by friend who deals

\begin{tabular}{lccc}
\hline Perceived likelihood of arrest & \multicolumn{3}{c}{ Buy from a friend who deals } \\
\cline { 2 - 4 } & No & Yes & Total \\
\hline None & $56(52.3 \%)$ & $24(22.4 \%)$ & $80(74.8 \%)$ \\
At least some & $12(11.2 \%)$ & $15(14.0 \%)$ & $27(25.2 \%)$ \\
Total & $68(63.6 \%)$ & $39(36.5 \%)$ & $107(100 \%)$ \\
\hline
\end{tabular}

Source: Authors.

Note: Pearson chi-square 5.692, $p=0.017$; Total $N=122$; both random and chain referral groups; some missing data. 
in my house. I only use it in my house unless I'm going to a movie or something, in which case I'll smoke it in my car. But then I'll only bring one joint at a time.' This avoidance or caution around public smoking is similar to the tactics adopted to avoid arrest found in a New York study of marijuana users [Ream et al. 2010], illustrating some operation of restrictive deterrence among experienced cannabis users elsewhere as well.

\section{Discussion}

This study documents a continuing lack of accurate knowledge of the cannabis laws among a fairly representative sample of adult users in a major Canadian city. These results do not square well with governing assumptions concerning the deterrent value of the law, nor with the practical suggestion that users would benefit from knowing precisely the legal consequences of arrest. One explanation for the lack of accurate knowledge might be a dearth of easily accessible information about conditions, penalties, and the status of the law. Exposure to conflicting interpretations may also be a consequence of numerous court challenges in recent years in Canada that have attempted to refute the legitimacy of the total cannabis ban [see also Hathaway 2001; Hathaway and Erickson 2003; Hyshka 2009a]. As well, media publicity around the time of our data collection about several proposed decriminalisation changes to the drug law, though none succeeded, may have created additional confusion about the current state of the law [Hyshka 2009b]. A similar interpretation to that of MacCoun et al. [2009] may be that their perceptions were more significant than the actual statutes. Further, many users in a large city like Toronto conceivably are aware that the typical penalties doled out for simple possession (i.e. small fines or discharge) are far more lenient than those that are officially available under Canada's Controlled Drugs and Substances Act. Our findings are compatible with the conclusion of the earlier cannabis deterrence literature of the 1970s, namely, that when arrest risk seems remote, concerns about severity of penalties diminishes [Lundman 1986].

Other than the differences in the reported impact of the law on individual use patterns, we detected no association between knowledge of the law and demographic characteristics such as age and sex, nor with respondents' level of consumption, as determined by amounts or frequency of use. The perceived risk of arrest for possessing cannabis was significantly related to other variables pertaining to the relative experience of users. We found that the most experienced (i.e. long-term, heavy, frequent users), and those who have been charged with possession in the past, perceived a greater risk or potential for arrest. Thus, the perceived certainty or fear of being arrested and knowledge of the law in shaping patterns of behaviour appear to have some influence, and this has certain implications for informing a more nuanced understanding of the meaning of deterrence. If the perceived risk of arrest increases with experience, rather than deterring casual or would-be users, it may be that the impact of the law is more apparent in 
making committed users more discreet about their use [see also Hathaway 2004; Hyshka, Erickson and Hathaway 2011].

To summarise, this study found that knowledge of the law was positively related to reporting that use patterns were to some degree affected by the cannabis laws. Whereas experienced users were not all well informed, most appear to have developed supply networks and use patterns that enable them to maintain a sense that they are 'safe'. The potential for arrest, for most, appeared to be unlikely, not because police in Toronto were inactive in enforcing the laws against possession, but because experienced users were accustomed to assessing and taking steps to minimise the risks. Building on the research literature, particularly Jacob's [2010] recent conceptualisation of restrictive deterrence, we contend there is a need for better understanding of marijuana use as a situated activity carried out within a framework of total prohibition of the recreational consumption of the drug. Whereas committed users are demonstrably unlikely to be threatened into quitting by the existing criminal sanctions against cannabis possession, evidently they are also risk-sensitive and often modify their practices to reduce the threat of detection.

It is not known whether the official record tally of convicted cannabis possession offenders in Canada is primarily comprised of users who are best described as simply unlucky, victims (i.e. those who have been unfairly targeted by police based on certain socio-demographic characteristics), those who have been charged originally with trafficking or other offences and had their charge reduced, or as unsuccessful risk negotiators who failed to exercise due caution, perhaps because they felt invincible. Nonetheless, a more sophisticated understanding of deterrence, or the influence of law in the experience of users, requires more research on perceptions of the law as a restrictive element that interacts with other forces shaping users' situated choices, definitions of controlled use, and related patterns of behaviour. Given the widespread use of cannabis in most Western nations, the extension of deterrence studies cross-nationally would seem to be fertile ground to increase knowledge about the operation of restrictive deterrence, placing more research emphasis on specific strategies to avoid arrest, local knowledge of the law and enforcement patterns, and behavioural changes prompted by the experience of arrest. Deterrence is a much more complex phenomenon than the classical model of punishment suggests. New directions, not just for drug crimes but a broader range of offences, can be examined applying the concept of restrictive deterrence and more sophisticated measures of users' practices and perceptions. The future of global cannabis regimes can be informed by revisiting deterrence research. 
PATRICIA ERICKSON is a professor of sociology and criminology at the University of Toronto, and scientist emerita at the Centre for Addiction and Mental Health where she has studied illicit drug use, the impact of drug policies, the links between drugs and violence, and the emergence of the harm reduction perspective.

MARK VAN DER MAAS is an advanced doctoral student in sociology and the collaborative programme in Addiction Studies at the University of Toronto. His thesis research focuses on problem gambling.

ANDRew Hathaway is an associate professor at the University of Guelph in the Department of Sociology and Anthropology. He currently leads a study of cannabis normalisation among university students at three Canadian campuses and other publications have emphasised the importance of human rights as central to drug policy reform.

\section{References}

Adlaf, Edward M., Patricia Begin and Ed Sawka. 2005. Canadian Addiction Survey (CAS). A national survey of Canadians' use of alcohol and other drugs: Prevalence of use and related harms: Detailed report. Ottawa: Canadian Centre on Substance Abuse.

Aldridge, Judith, Fiona Measham and Lisa Williams. 2011. Illegal Leisure Revisited: Changing Patterns of Alcohol and Drug Use in Adolescents and Young Adults. London: Routledge.

Andenaes, Johannes. 1974. Punishment and Deterrence. Ann Arbor, MI: University of Michigan Press.

Anderson, Linda S., Ted G. Chiricos and Gordon P. Waldo. 1977. 'Formal and Informal Sanctions: A Comparison of Deterrent Effects.' Social Problems 25 (1): 103-114.

Baker, Thomas and Alex R. Piquero. 2010. 'Assessing the Perceived Benefits-Criminal Offending Relationship.' Journal of Criminal Justice 38 (5): 981-987.

Barratt, Monica J., Francoise Chanteloup, Simon Lenton and Ali Marsh. 2005. 'Cannabis Law Reform in Western Australia: An Opportunity to Test Theories of Marginal Deterrence and Legitimacy.' Drug and Alcohol Review 24 (4):321-330.

Beccaria, Caesar. (1764) 1963. On Crimes and Punishments. Translated by H. Paolucci. Indianapolis, IN: Bobbs-Merrill.

Becker, Gary. 1968. 'Crime and Punishment: An Economic Approach.' Journal of Political Economy 76 (2): 169-217.

Böllinger, Lorenz. 2002. 'Recent Developments Regarding Drug Law and Policy in Germany and the European Community: The Evolution of Drug Control in Europe.' Journal of Drug Issues 32 (2): 363-378.

Bouchard, Martin and Holly Nguyen. 2010. 'Is It Who You Know, or How Many That Counts? Criminal Networks and Cost Avoidance in a Sample of Young Offenders.' Justice Quarterly 27 (1): 130-158.

Brochu, Serge, Cameron Duff, Mark Asbridge and Patricia G. Erickson. 2011. “"There's What's on Paper and Then There's What Happens, Out on the Sidewalk"': Cannabis Users' Knowledge and Opinions of Canadian Drug Laws.' Journal of Drug Issues 41 (1): 95-115.

Bushway, Shawn and Peter Reuter. 2008. 'Economists' Contribution to the Study of Crime and the Criminal Justice System.' Crime \& Justice 37: 389-453.

CADUMS. 2011. Canadian Alcohol and Drug Use Monitoring Survey. Ottawa: Canadian Centre on Substance Abuse. 
Caulkins, Jonathan P. and Rosalie Pacula. 2006. 'Marijuana Markets: Inferences from Reports by the Household Population.' Journal of Drug Issues 36 (1): 173-200.

Chambliss, William. 1966. 'The Deterrent Influence of Punishment.' Crime E Delinquency 12 (1): 70-75.

Chanteloup, Francoise, Simon Lenton, James Fetherson and Monica J. Barratt. 2005. 'Expected Impacts of the Cannabis Infringement Notice Scheme in Western Australia on Regular Users and Their Involvement in the Cannabis Market.' Drug and Alcohol Review 24 (4): 311-319.

Chiricos, Ted G. and Gordon P. Waldo. 1970. 'Punishment and Crime: An Examination of Some Empirical Evidence.' Social Problems 18 (2): 200-217.

Cohen, Peter and Arjan Sas. 1996. Cannabis Use, a Stepping Stone to Other Drugs. The Case of Amsterdam. University of Amsterdam: CEDRO, Centre for Drug Research.

Coomber, Ross and Paul Turnbull. 2007. 'Arenas of Drug Transactions: Adolescent Cannabis Transactions in England-Social Supply.' Journal of Drug Issues 37 (Fall): 845-865.

Csete, Joanne. 2012. A Balancing Act: Policymaking on Illicit Drugs in the Czech Republic. New York: Open Society Foundation.

Elliott, Luther, Andrew Golub and Eloise Dunlap. 2012. 'Off the Street and into "the Cut": Deterrence and Displacement in New York City's Quality of Life Marijuana Policing.' International Journal of Drug Policy 23 (3): 210-219.

EMCDDA. 2006. A Gender Perspective on Drug Use and Responding to Drug Problems. Lisbon: European Monitoring Centre for Drugs and Drug Addiction.

EMCDDA. 2012. Annual Report 2012: The State of the Drugs Problem in Europe. Lisbon: European Monitoring Centre for Drugs and Drug Addiction.

Erickson, Patricia G. 1976. 'Deterrence and Deviance: The Example of Cannabis Prohibition.' The Journal of Criminal Law and Criminology 67 (2): 222-232.

Erickson, Patricia. G. 1980. Cannabis Criminals: The Social Effects of Punishment on Drug Users. Toronto: Addiction Research Foundation.

Erickson, Patricia G. 1982. 'Illicit Drug Use, Peer Attitudes, and Perceptions of Harmful Effects among Convicted Cannabis Offenders.' Substance Use \& Misuse 17 (1): 141-154. [Formerly International Journal of the Addictions].

Erickson, Patricia G. 1989. 'Living with Prohibition: Regular Cannabis Users, Legal Sanctions, and Informal Controls.' Substance Use E Misuse 24 (3): 175-188. [Formerly International Journal of the Addictions].

Erickson, Patricia G. and Elaine Hyshka. 2010. 'Four Decades of Cannabis Criminals in Canada 1970-2010.' Amsterdam Law Forum 2 (4): 1-14.

Erickson, Patricia G. and Glenn F. Murray. 1986. 'Cannabis Criminals Revisited.' British Journal of Addiction 81 (1): 81-85.

Erickson, Patricia G., Diane M. Riley, Yuet W. Cheung and Patrick A. O'Hare (eds.). 2007. Harm Reduction: A New Direction for Drug Policies and Programs. Toronto: University of Toronto Press.

ESPAD. 2012. The 2011 ESPAD Report: Substance Use among Students in 36 European Countries. The European School Survey Project on Alcohol and Drug Use. Stockholm: The Swedish Council for Information on Alcohol and Other Drugs.

Fergusson, David M., Nicola R. Swain-Campbell and L. John Horwood. 2003. 'Arrests and Convictions for Cannabis Related Offences in a New Zealand Birth Cohort.' Drug and Alcohol Dependence 70 (1): 53-63.

Fielding, Amanda, Robin Room, Benedikt Fischer, Wayne Hall, Simon Lenton and Peter Reuter. 2008. The Global Cannabis Commission Report. Oxford: The Beckley Foundation Drug Policy Program.

Gallupe, Owen, Martin Bouchard and Jonathan P. Caulkins. 2011. ‘No Change Is a Good 
Change? Restrictive Deterrence in Illegal Drug Markets.' Journal of Criminal Justice 39 (1): 81-89.

Gibbs, John P. 1975. Crime, Punishment, and Deterrence. New York: Elsevier.

Giffen, P. James, Shirley Endicott and Sylvia Lambert. 1991. Panic and Indifference:

The Politics of Canada's Drug Laws: A Study in the Sociology of Law. Ottawa: Canadian Centre on Substance Abuse.

Harrison, Lana. 1997. 'The Validity of Self-reported Drug Use in Survey Research: An Overview and Critique of Research Methods.' Pp. 17-37 in NIDA Research Monograph 167, edited by Lana Harrison and Arthur Hughes. Rockville, MD: National Institute on Drug Abuse.

Hathaway, Andrew D. 1997. 'Marijuana and Lifestyle: Exploring Tolerable Deviance.' Deviant Behavior 18 (3): 213-232.

Hathaway, Andrew D. 2001. 'Charter Rights of Canadian Drug Users: A Constitutional Assessment of the Clay Trial and Ruling.' Canadian Journal of Law and Society 16 (1): 29-43.

Hathaway, Andrew D. 2004. 'Cannabis Careers Reconsidered: Transitions and Trajectories of Committed Long-Term Users.' Contemporary Drug Problems 31 (3): 401-423.

Hathaway, Andrew D. and Patricia G. Erickson. 2003. ‘Drug Reform Principles and Policy Debates: Harm Reduction Prospects for Cannabis in Canada.' Journal of Drug Issues 33 (2): 465-495.

Hathaway, Andrew D., Patricia G. Erickson and Phillipe Lucas. 2007. 'Canadian Public Opinion on Cannabis: How Far Out of Step with It Is the Existing Law?' Canadian Review of Social Policy 59: 44-55.

Hathaway, Andrew D., Elaine Hyshka, Patricia G. Erickson, Mark Asbridge, Serge Brochu, Marie-Marthe Cousineau and David Marsh. 2010. 'Whither RDS? An Investigation of Respondent Driven Sampling as a Method of Recruiting Mainstream Marijuana Users.' Harm Reduction Journal 7 (15): 1-11.

Hathaway, Andrew D., Maritt Kirst and Patricia G. Erickson. 2013. 'Marijuana Motives and Associated Outcomes: Relaxation and Enhancement versus Coping Outcomes.' Pp. 119-134 in Drug Use and Abuse: Signs/Symptoms, Physical and Psychological Effects and Intervention Approaches, edited by Marie Claire Van Hout. Hauppauge, NY: NOVA Science.

Hathaway, Andrew D. and Kirk I. Tousaw. 2008. 'Harm Reduction Headway and Continuing Resistance: Insights from Safe Injection in the City of Vancouver.' International Journal of Drug Policy 19 (1): 11-16.

Hyshka, Elaine. 2009a. 'The Saga Continues: Canadian Legislative Attempts to Reform Cannabis Law in the Twenty-First Century.' Canadian Journal of Criminology and Criminal Justice/La Revue Canadienne de Criminologie et de Justice Pénale 51 (1): 73-91.

Hyshka, Elaine. 2009b. 'Turning Failure into Success: What Does the Case of Western Australia Tell Us about Canadian Cannabis Policy-Making?’ Policy Studies 30 (5): 513-531.

Hyshka, Elaine, Patricia G. Erickson and Andrew D. Hathaway. 2011. 'The Time for Decriminalization Has Come Again ... and Again.' Criminal Law Bulletin 47 (2): 258-275.

Jacobs, Bruce A. 2010. 'Deterrence and Deterrability.' Criminology 48 (2): 417-441.

Johnston, Lloyd. 1980. 'Marijuana Use and the Effects of Marijuana Decriminalization.'

Testimony delivered at the hearings on the effects of marijuana held by the Subcommittee on Criminal Justice, Judiciary Committee, US Senate, 16 January, Washington, DC. 
Kilmer, Beau. 2003. Do Cannabis Possession Laws Influence Cannabis Use? Brussels: Ministry of Public Health.

Le Dain Commission. 1972. Cannabis. Final Report. Report of the commission of inquiry into the non-medical use of drugs. Ottawa: Information Canada.

Le Dain Commission. 1973. Cannabis. Final Report. Report of the commission of inquiry into the non-medical use of drugs. Ottawa: Information Canada.

Lenton, Simon. 2009. 'Cannabis Policy and the Burden of Proof: Is It Now beyond Reasonable Doubt That Cannabis Prohibition Is Not Working?' Drug and Alcohol Review 19 (1): 95-100.

Lenton, Simon and Penny Heale. 2000. 'Arrest, Court and Social Impacts of Conviction for a Minor Cannabis Offense under Strict Prohibition.' Contemporary Drug Problems 27 (4): 805-833.

Loughran, Thomas A., Raymond Paternoster, Alex R. Piquero and Greg Pogarsky. 2011. 'On Ambiguity in Perceptions of Risk: Implications for Criminal Decision Making and Deterrence.' Criminology 49 (4): 1029-1061.

Lundman, Richard J. 1986. 'One-Wave Perceptual Deterrence Research: Some Grounds for the Renewed Examination of Cross-sectional Methods.' Journal of Research in Crime and Delinquency 23 (4): 370-388.

MacCoun, Robert, Rosalie L. Pacula, Jamie Chriqui, Katherine Harris and Peter Reuter. 2009. 'Do Citizens Know Whether Their State Has Decriminalized Marijuana? Assessing the Perceptual Component of Deterrence Theory.' Review of Law E Economics 5 (1): 340-364.

MacCoun, Robert and Peter Reuter. 2001. 'Evaluating Alternative Cannabis Regimes.' The British Journal of Psychiatry 178 (2): 123-128.

Meier, Robert F. and Weldon T. Johnson. 1977. 'Deterrence as Social Control: The Legal and Extralegal Production of Conformity.' American Sociological Review 42 (4): 292-304.

Murray, Glenn F. and Patricia G. Erickson. 1987. 'Cross-sectional versus Longitudinal Research: An Empirical Comparison of Projected and Subsequent Criminality.' Social Science Research 16 (2): 107-118.

Parker, Howard. 2005. 'Normalization as a Barometer: Recreational Drug Use and the Consumption of Leisure by Younger Britons.' Addiction Research E Theory 13 (3): 205-215.

Pauwels, Lieven, Frank Weerman, Gerben Bruinsma and Wim Bernasco. 2011. ‘Perceived Sanction Risk, Individual Propensity and Adolescent Offending: Assessing Key Findings from the Deterrence Literature in a Dutch Sample.' European Journal of Criminology 8 (5): 386-400.

Peretti-Watel, Patrick. 2003. 'Neutralization Theory and the Denial of Risk: Some Evidence from Cannabis Use among French Adolescents.' The British Journal of Sociology 54 (1): 21-42.

Piquero, Alex R., Raymond Paternoster, Greg, Pogarsky and Thomas Loughran. 2011. 'Elaborating the Individual Difference Component in Deterrence Theory.' Annual Review of Law and Social Science 7: 335-360.

Pogarsky, Greg. 2002. 'Identifying 'Deterrable' Offenders: Implications for Research on Deterrence.' Justice Quarterly 19 (3): 431-452.

Pratt, Travis C., Francis T. Cullen, Kristie R. Blevins, Leah E. Daigle and Tamara D. Madensen. 2006. 'The Empirical Status of Deterrence Theory: A Meta-analysis.' Pp. 367-395 in Taking Stock: The Status of Criminological Theory, Vol.15, edited by Francis Cullen, John P. Wright and Kristie R. Blevins. New Brunswick, NJ: Transaction Publishers.

Ream, Geoffrey L., Bruce D. Johnson, Eloise Dunlap and Ellen Benoit. 2010. ‘The Role of 
Marijuana Use Etiquette in Avoiding Targeted Police Enforcement.' Drugs: Education, Prevention and Policy 17 (6): 689-706.

Reinarman, Craig. 2009. 'Cannabis Policies and User Practices: Market Separation, Price, Potency, and Accessibility in Amsterdam and San Francisco.' International Journal of Drug Policy 20 (1): 28-37.

Reinarman, Craig, Peter D. Cohen and Hendrien L. Kaal. 2004. 'The Limited Relevance of Drug Policy: Cannabis in Amsterdam and in San Francisco.' American Journal of Public Health 94 (5): 836-842.

Ritson, Bruce. 2003. 'The 1999 ESPAD Report. The European School Survey Project on Alcohol and Other Drug Use among Students in 30 European Countries.' Alcohol and Alcoholism 38 (1): 99-99.

Sandberg, Sveinung. 2012. 'Cannabis Culture: A Stable Subculture in a Changing World.' Criminology and Criminal Justice. Retrieved 28 May 2012 (http://crj.sagepub.com/ content/early/2012/05/24/1748895812445620).ly/2012/05/24/1748895812445620).

Sarkany, Peter. 2012. 'The Strict Swedish vs the Loose Dutch System for Regulations on Prostitution and Drug Use.' Journal of Mathematics and System Science 2 (1): 26-35.

Sherman, Lawrence W. 1993. 'Defiance, Deterrence, and Irrelevance: A Theory of the Criminal Sanction.' Journal of Research in Crime and Delinquency 30 (4): 445-473.

Shiner, Michael and Tim Newburn. 1997. 'Definitely, Maybe Not? The Normalisation of Recreational Drug Use amongst Young People.' Sociology 31 (3): 511-529.

Silberman, Matthew. 1976. 'Toward a Theory of Criminal Deterrence.' American Sociological Review 41 (3): 442-461.

Single, Eric W. 1989. 'The Impact of Marijuana Decriminalization: An Update.' Journal of Public Health Policy 10 (Winter): 456-466.

Stafford, Mark C. and Mark Warr. 1993. 'A Reconceptualization of General and Specific Deterrence.' Journal of Research in Crime and Delinquency 30 (2): 123-135.

Statistics Canada. 2010. 'Police-Reported Crime for Selected Offences, Canada, 2010.' Retrieved 4 January 2012 (http://www.statcan.gc.ca/daily-quotidien/110721/ t110721b1-eng.htm).

Teevan, James J. 1976. 'Subjective Perception of Deterrence (Continued).' Journal of Research in Crime and Delinquency 13 (2): 155-164.

The Economist. 2013. 'Towards a Ceasefire: Winding Down the War on Drugs.' 23 February-1 March, pp. 57-59.

Tittle, Charles. 1980. Sanctions and Social Deviance: The Question of Deterrence. New York: Praeger.

UNODC. 2012. World Drug Report. New York: United Nations Office on Drug and Crime. van Vliet, Henk J. 1990. 'Separation of Drug Markets and the Normalization of Drug Problems in the Netherlands: An Example for Other Nations?' Journal of Drug Issues 20 (3): 463-471.

Waldo, Gordon P. and Ted G. Chiricos. 1972. 'Perceived Penal Sanction and Self-reported Criminality: A Neglected Approach to Deterrence Research.' Social Problems 19 (4): 522-540.

Yacoubian, Jr., George S. 2008. 'Assessing the Relationship between Marijuana Availability and Marijuana Use: A Legal and Sociological Comparison between the United States and the Netherlands.' Journal of Alcohol E Drug Education 51 (4): 17-34.

Zimring, Franklin E. and Gordon Hawkins. 1973. Deterrence: The Legal Threat in Crime Control. Chicago, IL: University of Chicago Press. 